\title{
PENINGKATAN KEWASPADAAN TERHADAP SINDROM METABOLIK PADA LANSIA DI KEUSKUPAN AGUNG JAKARTA
}

\author{
Twidy Tarcisia ${ }^{1}$, Idawati Karjadidjaja ${ }^{2}$, Alexander Halim Santoso ${ }^{3}$ \\ ${ }^{1}$ Jurusan Kedokteran, Universitas Tarumanagara Jakarta \\ Email: twidyt@fk.untar.ac.id, \\ 2 Jurusan Kedokteran, Universitas Tarumanagara Jakarta \\ Email: idawatik@fk.untar.ac.id \\ ${ }^{3}$ Jurusan Kedokteran, Universitas Tarumanagara Jakarta \\ Email: alexanders@fk.untar.ac.id
}

\begin{abstract}
ABSTRAK
Penambahan umur harapan hidup menyebabkan peningkatan populasi lanjut usia (lansia) yang berpengaruh terhadap angka kejadian penyakit degeneratif seperti sindrom metabolik. Sindrom metabolik adalah kumpulan gangguan metabolik seperti hipertrigliserida, hyper-low-density lipoprotein (LDL), hypo-high-density lipoprotein $(H D L)$, resistensi insulin, gangguan toleransi glukosa, hipertensi dan abdominal obesity. Prevalensi sindrom metabolik pada dekade terakhir dilaporkan meningkat terutama di negara berkembang. Tindakan preventif yang dapat dilakukan untuk menurunkan angka kejadian sindrom metabolik adalah dengan melakukan pemeriksaan kesehatan dini. Komisi kesehatan Keuskupan Agung Jakarta (KK KAJ) adalah upaya peningkatan kesehatan masyarakat melalui pengembangan program preventif seperti pemeriksaan kesehatan. Dari uraian tersebut kami bekerja sama dengan KK KAJ menyelenggarakan kegiatan PKM berupa pemeriksaan kesehatan dalam bentuk pemeriksaan fisik dan pemeriksaan darah dengan target peserta lansia untuk mendeteksi adanya sindrom metabolik sehingga dapat mengurangi angka resiko kecacatan dan kematian. Pemeriksaan fisik yang dilakukan dalam kegiatan ini adalah pemeriksaan tekanan darah. Sedangkan pemeriksaan darah yang dilakukan mencakup pemeriksaan gula darah dan kolesterol seperti glukosa darah, HDL, LDL dan trigliserida. Peserta yang telah melakukan pemeriksaan darah dapat berkonsultasi dengan tim dokter untuk menginterpretasikan hasil pemeriksaan. Jumlah peserta yang berpartisipasi pada kegiatan ini adalah 320 peserta. Hasil yang dicapai dari kegiatan ini adalah peserta mengetahui hasil pemeriksaan kesehatan baik pemeriksaan fisik maupun pemeriksaan darah yang dapat menggambarkan status kesehatan peserta. Dengan diketahuinya status kesehatan diri sendiri, diharapkan dapat meningkatkan kewaspadaan diri terhadap sindrom metabolik baik melalui tindakan promotif dan preventif.
\end{abstract}

Kata kunci: Lansia; Keuskupan Agung Jakarta (KAJ); Pemeriksaan kesehatan; Sindrom metabolik.

\section{PENDAHULUAN}

Keberhasilan pembangunan dinilai dari peningkatan taraf hidup dan umur harapan hidup. Peningkatan umur harapan hidup akan menyebabkan transisi epidemiologi akibat peningkatan populasi lanjut usia (lansia). Masalah yang sering dihadapi lansia adalah penurunan fungsi organ akibat proses degeneratif seperti sindrom metabolik (Unika Atmajaya,2018). Sindrom metabolik adalah kumpulan gangguan metabolik seperti hipertrigliserida, hyper-low-density lipoprotein (LDL), hypo-high-density lipoprotein (HDL), resistensi insulin, gangguan toleransi glukosa, hipertensi dan abdominal obesity (Coltuc,2016). Sindrom ini berperan sebagai parameter faktor resiko penyakit kardiovaskuler, diabetes melitus tipe 2, aterosklerosis, penyakit ginjal dan hati.(Bonomini,2015) Prevalensi sindrom metabolik pada dekade terakhir dilaporkan meningkat terutama di negara berkembang dan hal ini mengacu pada peningkatan angka resiko kecacatan dan kematian penduduk (Coltuc,2016). Pada proses penuaan, terjadi penurunan fungsi fisiologis tubuh yang dapat mengarah menjadi masalah kesehatan seperti sindrom metabolik (Bonomini,2015).

Proses penuaan terjadi akibat akumulasi kerusakan sel oleh radikal bebas. Radikal bebas merupakan hasil samping proses metabolisme yang melibatkan oksigen seperti senyawa oksigen reaktif (SOR) dan senyawa nitrogen reaktif (SNR). Senyawa radikal akan menyebabkan kerusakan sel bahkan kematian sel (Larasati,2017). Patofisiologi sindrom metabolik sangat komplek dan 
belum diketahui pasti. Beberapa tahun terakhir ditemukan peranan radikal bebas pada patogenesis vaskular yang dapat memperburuk sindrom metabolik (Coltuc,2016).

Kriteria untuk menegakkan sindrom metabolik adalah obesitas perut; kadar trigliserida $\geq 150$ $\mathrm{mg} / \mathrm{dl}$ atau mendapat terapi trigliserida; $\mathrm{HDL}<40 \mathrm{mg} / \mathrm{dL}$ (laki-laki) dan $50 \mathrm{mg} / \mathrm{dL}$ (perempuan); tekanan darah $\geq 130 / 85 \mathrm{mmHg}$ atau mendapat terapi hipertensi dan glycemia $\geq 100 \mathrm{mg} / \mathrm{dl}$ atau diabetes melitus tipe 2 (Bonomini,2015). Untuk menegakkan kadar trigliserida, HDL dan glycemia diperlukan pemeriksaan darah berupa pemeriksaan kolesterol dan gula darah. Pemeriksaan menggunakan metode Point of Care Testing (PCOT). Metode PCOT memungkinkan didapatkan hasil pemeriksaan secara cepat tanpa menunggu lama (Yasin,2018). Tekanan darah dapat dinilai dengan melakukan pengukuran menggunakan tensimeter dan stetoskop.

Keuskupan Agung Jakarta (KAJ) adalah wilayah formal Gereja Katolik Roma di Indonesia yang mencakup wilayah Jakarta, Tangerang, Bekasi dan Cikarang (Wikipedia,2019). Komisi Kesehatan KAJ (KKKAJ) mendukung upaya peningkatan kesehatan masyarakat melalui pengembangan program preventif dan promotif (Unika Atmajaya,2018). Saat ini penyakit tidak menular menempati 10 besar penyakit penyebab kematian terbanyak di Indonesia, termasuk kedalamnya sindrom metabolik. Diperlukan pemeriksaan kesehatan oleh masyarakat terutama masyarakat lansia untuk mendeteksi adanya sindrom metabolik sehingga dapat mengurangi angka resiko kecacatan dan kematian (Unika Atmajaya,2018; Larasati,2017; Yonei,2015). Maka dari itu, Fakultas Kedokteran Universitas Tarumanagara dan KAJ bekerja sama melakukan pemeriksaan kesehatan baik fisik maupun darah yang mencakup pemeriksaan tekanan darah, kolesterol dan gula darah untuk mencegah terjadinya sindrom metabolik pada lansia terutama komunitas lansia KAJ (Bonomini,2015; Yonei,2015).

\section{METODE PELAKSANAAN PKM}

Kegiatan ini dibiayai oleh Direktorat Penelitian dan Pengabdian kepada Masyarakat Universitas Tarumanagara (DPPM UNTAR) dan KAJ. Kegiatan diadakan di Aula Lantai 4 GKP Paroki Santo Yakobus, Jakarta Utara. Relawan tenaga kesehatan yang bertugas sebagai dokter pemeriksa berasal dari tenaga kesehatan Paroki Kelapa Gading dan Fakultas Kedokteran Universitas Tarumanagara. Terdapat 6 tim dokter pemeriksa yang terdiri dari 3-4 dokter pemeriksa (Gambar 1). Tiap dokter memiliki tanggung jawab masing-masing seperti pemeriksaan fisik, darah dan konsultan hasil pemeriksaan.

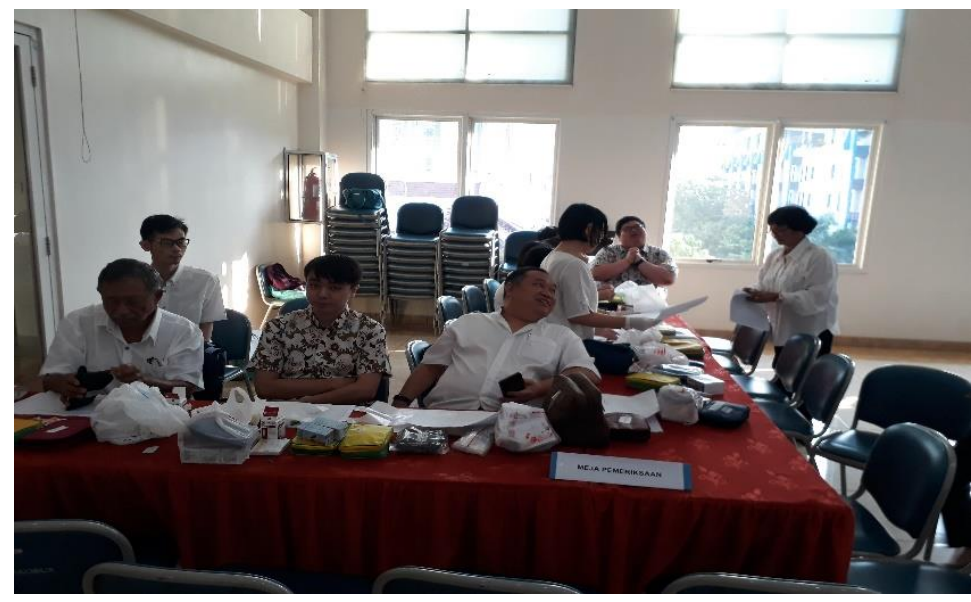

Gambar 1. Tim Dokter Pemeriksa 
Jumlah peserta lansia yang hadir pada kegiatan ini sebanyak 320 peserta. Peserta lansia yang berpartisipasi dalam kegiatan adalah umat katolik lansia dari wilayah KAJ. Usia peserta lansia yang melakukan pemeriksaan fisik dan darah diwajibkan di atas 65 tahun (Gambar 2). Peserta lansia berasal dari berbagai latar belakang sosial, budaya dan ekonomi. Peserta sebelumnya telah mendaftarkan diri ke seksi kesehatan paroki masing-masing untuk mengikuti kegiatan ini. Setelah peserta mendapat hasil pemeriksaan, peserta dapat berkonsultasi dengan tim dokter untuk menjelaskan interpretasi hasil pemeriksaan tersebut.

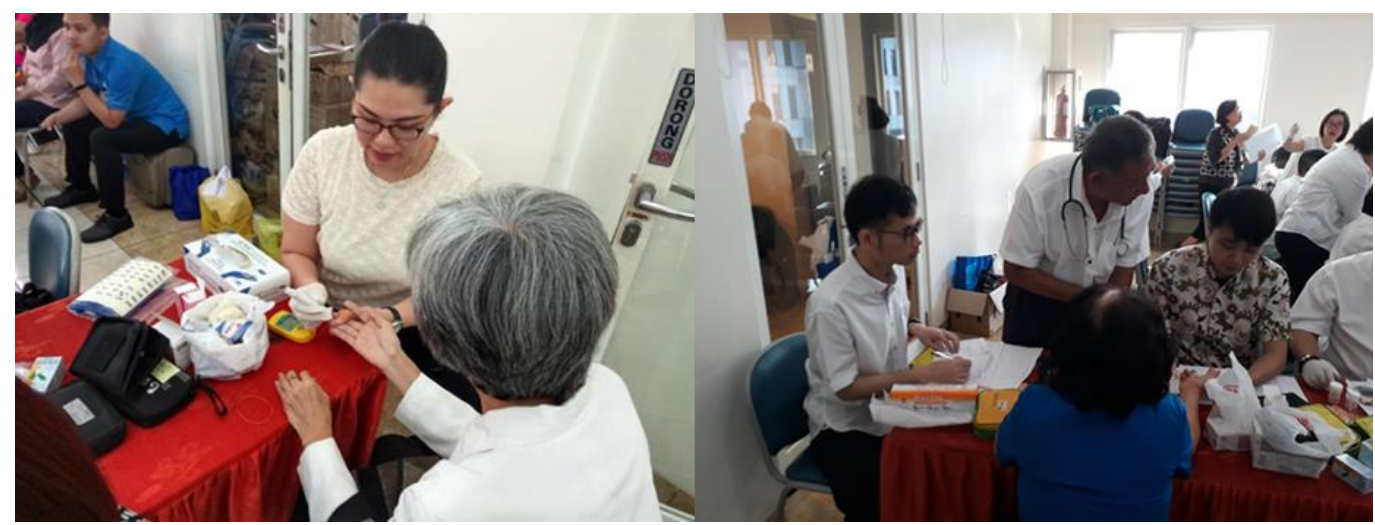

Gambar 2. Kegiatan Pemeriksaan Kesehatan

\section{HASIL DAN PEMBAHASAN}

Bentuk kegiatan yang akan dilakukan berupa pemeriksaan fisik dan darah serta konsultasi interpretasi hasil pemeriksaan (bila diperlukan). Kegiatan ini bertujuan untuk membangkitkan kesadaran warga lansia terhadap risiko penyakit sindrom metabolik melalui perilaku kesehatan preventif dan promotif. Peserta lansia akan mendapat hasil pemeriksaan fisik dan darah sehingga diharapkan meningkatkan kewaspadaan diri terhadap kesehatannya masing-masing terutama sindrom metabolik.

Sindrom metabolik adalah gangguan metabolisme yang memiliki gejala berupa obesitas, hipertensi, hiperglikemia dan dislipidemia. Lansia yang mengalami obesitas memiliki risiko 4 kali lebih besar dari lansia yang tidak mengalami obesitas. Obesitas pada lansia cenderung disebabkan karena aktivitas fisik yang mulai berkurang namun tidak diikuti penurunan asupan makanan. Selain itu proses penuaan menyebabkan penurunan massa otot dan peningkatan massa lemak tubuh (Widyastuti,2013) riwayat merokok dan faktor genetik juga merupakan penyebab sindrom metabolik (Putri,2017). Adanya pemeriksaan kesehatan dan konsultasi tim dokter pada kegiatan ini kami harapkan meningkatkan kesadaran para lansia untuk mengadopsi perilaku sehat seperti: mengatur pola makan, menambah aktivitas fisik, berhenti merokok dan rutin kontrol penyakit yang diderita ke pelayanan kesehatan.

Peserta lansia yang mengikuti kegiatan ini sebanyak 320 peserta (Gambar 3). Kegiatan PKM diawali dengan pendaftaran ulang peserta dengan membawa bukti daftar dari paroki asal. Pada pendaftaran ulang ini peserta akan mendapat kupon makan siang yang bertuliskan nomor panggil pemeriksaan (Gambar 4). Setelah mendapat kupon makan dan nomor pemeriksaan, peserta menunggu untuk dipanggil di tempat yang telah disediakan. Peserta diminta menulis identitas di kertas pemeriksaan (kuosinoner peserta). Kertas tersebut digunakan untuk mencatat hasil pemeriksaan masing-masing peserta baik pemeriksaan fisik maupun darah oleh dokter pemeriksa (Gambar 5). Peserta lansia juga dapat berkonsultasi dengan tim dokter mengenai hasil pemeriksaan kesehatan yang telah diterima. 


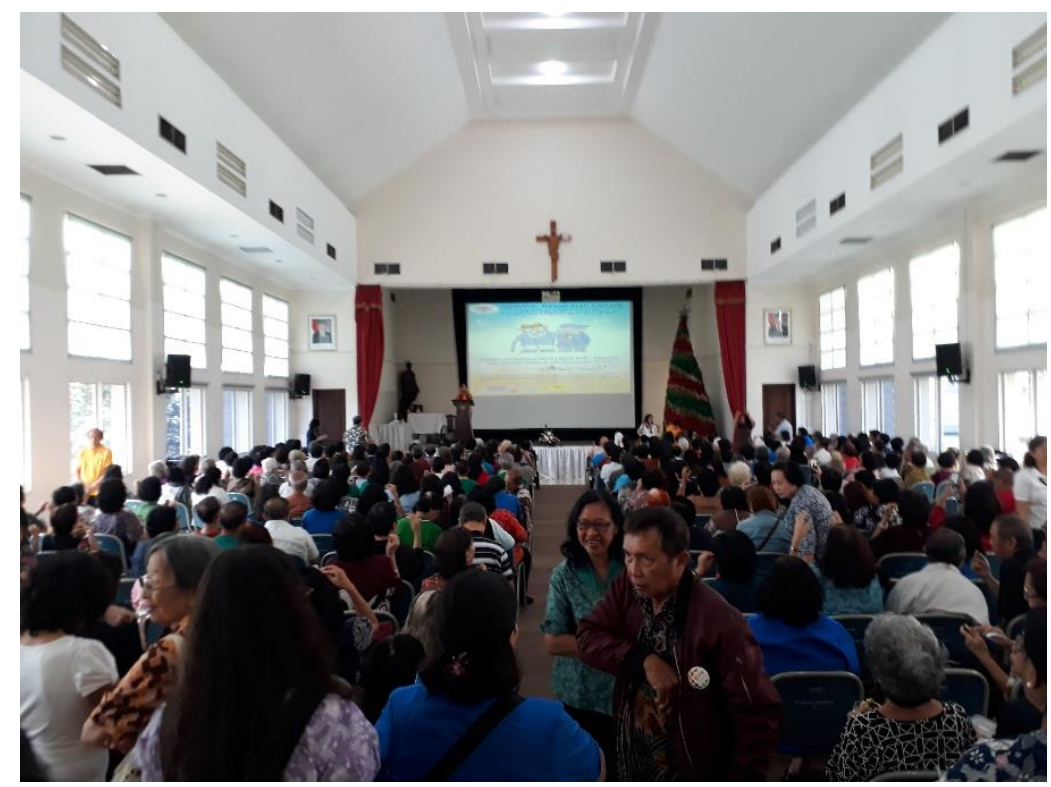

Gambar 3. Peserta PKM

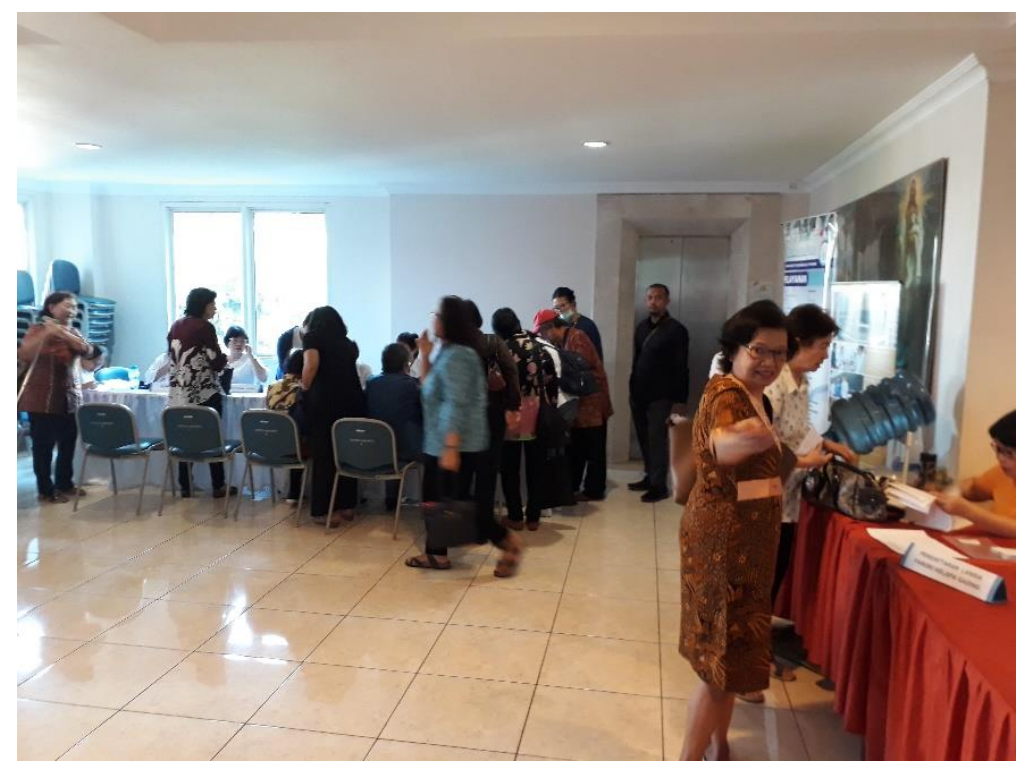

Gambar 4. Pendaftaran Ulang Peserta PKM

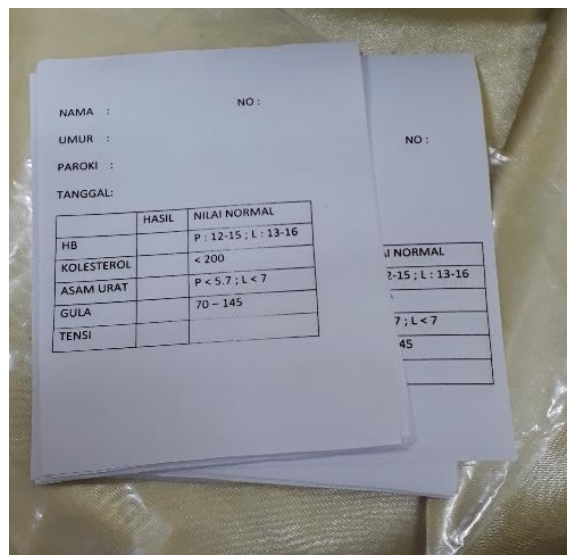

Gambar 5. Kertas Pemeriksaan (Kuisioner Peserta) 
Kegiatan PKM ini ditutup dengan misa pengurapan orang sakit yang dipimpin oleh VIKJEN KAJ Rm. Samuel Pangestu, Pr. Dalam misa tersebut gereja mengingatkan para lansia KAJ untuk selalu bersyukur dan menjaga kesehatan masing-masing peserta lansia baik secara rohani maupun jasmani (Gambar 6). Makan siang dan suvenir untuk peserta lansia dibagikan setelah misa pengurapan orang sakit selesai.

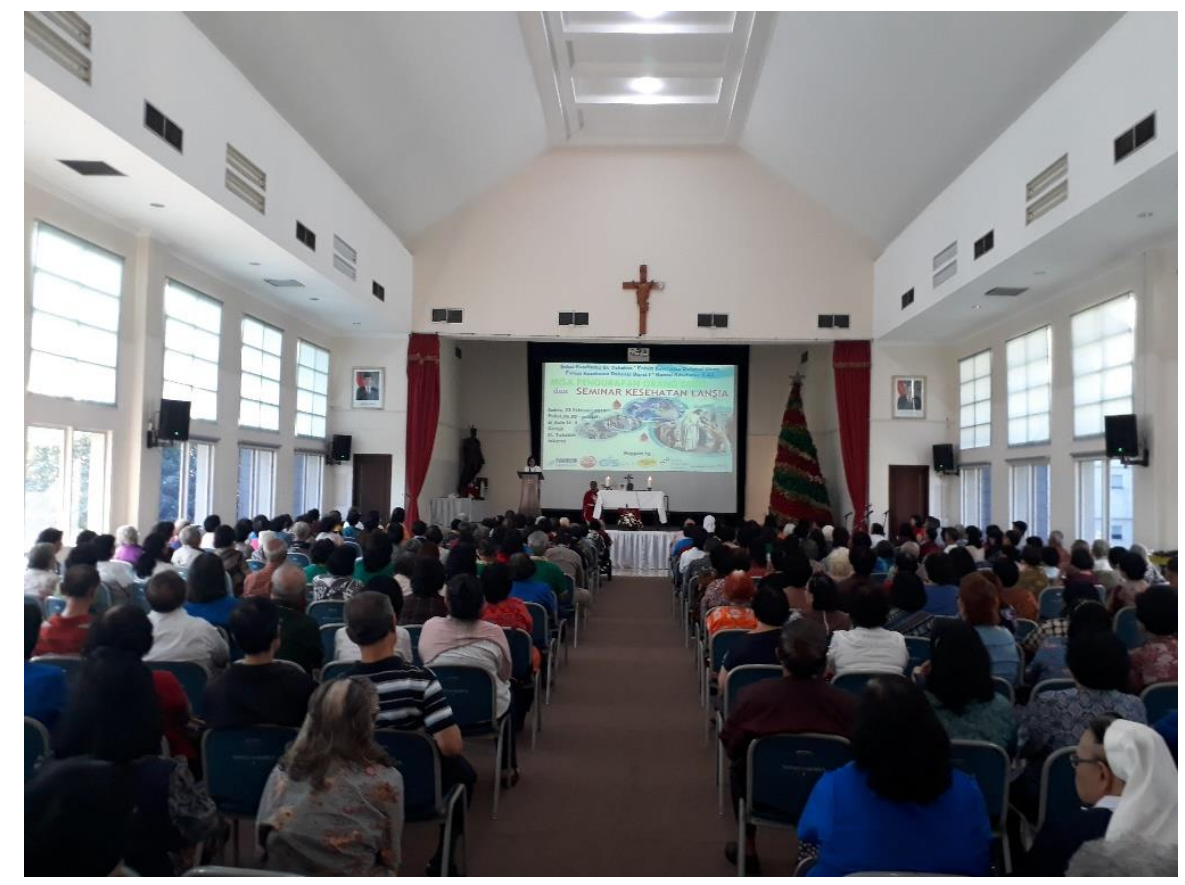

Gambar 6. Misa Pengurapan Orang Sakit

\section{KESIMPULAN DAN SARAN}

Sindrom metabolik adalah gangguan metabolisme yang disebabkan oleh perilaku hidup tidak sehat dan faktor genetik. Upaya peningkatan kewaspadaan diri lansia KAJ terhadap sindrom metabolik dilakukan dengan menerapkan perilaku kesehatan preventif dan promotif. Perilaku kesehatan tersebut adalah melakukan konsultasi dan pemeriksaan kesehatan rutin ke tenaga kesehatan. Konsultasi dan pemeriksaan kesehatan yang dilakukan tim dokter dapat menggambar status kesehatan lansia KAJ sehingga meningkatkan kesadaran untuk menerapkan perilaku hidup sehat.

Selanjutnya diharapkan adanya kegiatan pengabdian masyarakat yang berkelanjutan untuk menindaklanjuti kegiatan yang telah dilakukan saat ini sebagai upaya promotif dan preventif dalam menunjang keberhasilan pembangunan melalui peningkatan taraf hidup dan umur harapan hidup. Kegiatan ini perlu juga dilakukan secara multidisiplin baik di dalam fakultas kedokteran sehingga tercapai keberhasilan pembangunan secara menyeluruh, seperti mengadakan seminar pola hidup sehat dan balai pengobatan.

\section{Ucapan Terima Kasih (Acknowledgement)}

Kami ucapkan terima kasih kepada DPPM Universitas Tarumanagara yang telah mendukung secara finansial sehingga terlaksanalah kegiatan PKM ini. Kami juga mengucapkan terima kasih kepada Fakultas Kedokteran Universitas Tarumanagara, KAJ dan seksi kesehatan Paroki Kelapa Gading yang telah memberikan bimbingan dan sarana prasarana dalam kegiatan ini. 


\section{REFERENSI}

Bonomini, F., Rodella, L.F. \& Rezzani, R. (2015). Metabolic Syndrome, Aging and Involvement of Oxidative Stress. Aging Dis, 6(1), 109-20

Coltuc, R.V. \& Stoica, V. (2016). Metabolic Syndrome-Cardiovascular and Metabolic, Complex, Difficult to Quantify Risk Factor. Modern Medicine, 23(2), 54-59

Larasati, T.A., Angraini, D.I. \& Sudarsono, D.F. (2017). Penatalaksanaan Holistik pada Lansia dengan Sindrom Metabolik dan Osteoartritis. J AgromedUnila, 4(1), 71-80

Putri MA, Lestari A, Stephani, Murhani. (2017). Gambaran pola makan, aktivitas fisik, riwayat penyakit keluarga dan kebiasaan merokok pada penderita sindrom metabolik di instansi non kesehatan. Jurnal Proteksi Kesehatan, 6(1), 22-41

Universitas Katolik Indonesia Atma Jaya. (2018). Diakses dari https://m.atmajaya.ac.id/web/Konten.aspx?gid=highlight\&cid=Menjadi-Lansia-yangSehat-dan-Produktif

Widyastuti N, Sulchan M, Johan A. (2013). Asupan makan, sindrom metabolik dan status keseimbangan asam-basa pada lansia. JGKI, 9(4), 179-87

Wikipedia. (2019). Diakses dari: https://id.wikipedia.org/wiki/Keuskupan_Agung_Jakarta

Yasin, F. (2018). Pemeriksaan Glukosa Dengan Point Of Care Testing (POCT). Diakses dari: $\mathrm{http}$ ://yankes.kemkes.go.id/read-pemeriksaan-glukosa-dengan-point-of-care-testing-poct5475.html

Yonei, Y. \& Takabe, W. (2015). Aging Assessment by Anti-Aging Medical Checkup. HEP, 42, 459-64 